First Peoples Child \& Family Review

An Interdisciplinary Journal Honouring the Voices, Perspectives, and Knowledges of

First Peoples through Research, Critical Analyses, Stories, Standpoints and Media

Reviews

\title{
Indigenous Wholistic Theory: A Knowledge Set for Practice
}

\section{Kathy Absolon}

Volume 5, Number 2, 2010

URI: https://id.erudit.org/iderudit/1068933ar

DOI: https://doi.org/10.7202/1068933ar

See table of contents

\section{Publisher(s)}

First Nations Child and Family Caring Society of Canada

\section{ISSN}

1708-489X (print)

2293-6610 (digital)

Explore this journal

Cite this article

Absolon, K. (2010). Indigenous Wholistic Theory: A Knowledge Set for Practice. First Peoples Child \& Family Review, 5(2), 74-87.

https://doi.org/10.7202/1068933ar

\section{Article abstract}

In this article, the author, establishes a knowledge set for Indigenous social work practice based on Indigenous wholistic theory. An overall framework using the circle is proposed and introduced followed by a more detailed and elaborated illustration using the four directions. The article identifies the need to articulate Indigenous wholistic theory and does so by employing a wholistic framework of the four directional circle. It then systematically moves around each direction, beginning in the east where a discussion of Spirit and Vision occurs. In the south a discussion of relationships, community and heart emerge. The western direction brings forth a discussion of the spirit of the ancestors and importance of Indigenous knowledge and Indigenous knowledge production. The northern direction articulates ideas surrounding healing and movements and actions that guide practice. Finally, the article begins with a discussion on all four directions together with a final examination of the center fire where all elements interconnect and intersect. Lastly, the article proclaims the existence of Indigenous wholistic theory as a necessary knowledge set for practice.
This document is protected by copyright law. Use of the services of Érudit (including reproduction) is subject to its terms and conditions, which can be viewed online.

https://apropos.erudit.org/en/users/policy-on-use/ 


\title{
First Peoples Child \& Family Review
}

An Interdisciplinary Journal Honoring the Voices, Perspectives and Knowledges of First Peoples through Research, Critical Analyses, Stories, Standpoints and Media Reviews

\section{Volume 5, Number 2, 2010, pp. 74-87}

\section{Indigenous Wholistic Theory: A Knowledge Set for Practice}

\author{
Kathy Absolona
}

\begin{abstract}
a Assistant Professor, Faculty of Social Work, Wilfrid Laurier University, Waterloo, Ontario. Dr. Kathy Absolon is Anishinaabe kwe from Flying Post First Nation and teaches in the Aboriginal Field of Study. She has a background in Indigenous studies and Aboriginal social work practice. Kathy teaches holistic healing practices and Indigenous holistic thought. Her practice experience has been in working with individuals, families, groups and communities within Indigenous contexts.
\end{abstract}

\section{Introduction}

This article joins other recent and worthy publications where authors advance Indigenous ways of knowing, being and doing (Graveline, 2004; Hart, 2002; Nabigon, 2006; Poonwassie \& Charter, 2005; Sinclair, Hart, \& Bruyere, 2009; Solomon \& Wane, 2005). As Indigenous practice increasingly becomes asserted and expressed, we need to continue to articulate elements of Indigenous wholistic theory that guides Indigenous based social work practice.

Indigenous peoples have worldviews and means of relating to the world. Stemming from this worldview comes the understanding that 'we are all related'. Indigenous theory is rooted intimately within Indigenous epistemologies, worldviews, cultures and traditions. Indigenous wholistic theory is wholistic and multi-layered, which encompasses the spiritual, emotional, mental and physical elements of being. We also acknowledge our past, present and future. By that very nature, we must look at the past and into our future and Indigenous theory factors in seven generations past and the seven generations into the future.

Questions or correspondence concerning this article may be addressed to:

Kathy Absolon

519.884.0710 ext.5229

kabsolon@wlu.ca

\begin{abstract}
In this article, the author, establishes a knowledge set for Indigenous social work practice based on Indigenous wholistic theory. An overall framework using the circle is proposed and introduced followed by a more detailed and elaborated illustration using the four directions. The article identifies the need to articulate Indigenous wholistic theory and does so by employing a wholistic framework of the four directional circle. It then systematically moves around each direction, beginning in the east where a discussion of Spirit and Vision occurs. In the south a discussion of relationships, community and heart emerge. The western direction brings forth a discussion of the spirit of the ancestors and importance of Indigenous knowledge and Indigenous knowledge production. The northern direction articulates ideas surrounding healing and movements and actions that guide practice. Finally, the article begins with a discussion on all four directions together with a final examination of the center fire where all elements interconnect and intersect. Lastly, the article proclaims the existence of Indigenous wholistic theory as a necessary knowledge set for practice.
\end{abstract}

Keywords: Indigenous wholistic theory, social work practice, theory, four directional circle, relationships, community, healing.

It forms a framework to 'indigenize' our thoughts and actions into active healing processes that simultaneously decolonize and indigenize. And finally but not exclusively, I know that Indigenous theory is earth based and derived from the teachings of the land, sun, water, sky and all of Creation. Its' methodologies of practice integrate the natural teachers and elements of the earth. Indigenous wholistic theory is an ancestral concept to Indigenous people where,

Aboriginal people in Canada have ancient culture specific philosophical foundations and practices, which continue to provide them with guidance in everyday life. In their healing process these imperatives provide guidance to those who experience physical, psychological, emotional, or spiritual distress - individually, in a family, or in a community (Poonwassie \& Charter, 2001, p. 63). 
Our work as wholistic practitioners is to remember and reconnect with wholistic knowledges, pick up our bundles and activate them again. Picking up our bundles means to relearn, reclaim, pick up and own the teachings and practices that emanate from wholistic theory and knowedge. It means to live and practice minobimaadsiwin (a good life). In this article, a wholistic framework organizes and presents the knowledge set for Indigenous wholistic theory in Indigenous social work practice.

This article, in fact, stems from an earlier article I wrote in 1993 called Healing as practice: Teachings from the Medicine $W_{h e e}{ }^{1}$, which I never formally published but was widely requested and used. Within this article I use the terms Indigenous and Anishinaabek as inclusive to all Aboriginal, First Nations, Métis and Inuit peoples. My use of the spelling wholism indicates 'whole' as in wholistic, complete, balanced and circular. First I present an overview. Second, I identify who I am. Lastly I present initial tenets of Indigenous wholism with a wholistic model and discussion.

\section{Overview}

This article is written for those that seek to understand a wholistic perspective of practice from an Indigenous lens and is organized using a wholistic paradigm of the four directions circle which encompasses concepts such as cyclical, circular and relational. Wholistic theory includes an intermixing and consideration of time and space: the past, present, future; directions and doorways of life; the ecology of creation such as earth, sun, water and air and all their occupants; and values that retain the balance and harmony of all of the above. My goal is to highlight a knowledge set that informs Indigenous wholistic theory for practice. This knowledge is based in oral traditions, is sacred and can take years to understand and know. I feel limited to fully and adequately articulate a complete portrait of the elements of Indigenous theory. However, I encourage readers to embrace opportunities to learn and follow-up with references cited to develop their own knowledge set. The presented framework does not delve into the specifics of each area of knowledge because specific knowledge sets can be learning processes in themselves. This knowledge set can be used to guide practice and further practice lenses can be developed for purposes of wholistic assessment, evaluation and treatment and change; and may be applied at levels of self, individual, family, community, organization and institution.

\section{Who am I?}

During my contemplations of writing this article I wondered: Who am I to write such an article? An Indigenous

\footnotetext{
1 Absolon, Kathy (1993). Healing as Practice: Teachings from the Medicine Wheel. A commissioned paper for the WUNSKA network, Canadian Schools of Social Work. Unpublished manuscript.
}

worldview seeks that you identify yourself to the Spirit, the people and the Spirit of the work you intend on doing and this act establishes the beginning of respectful practice. As I send out these words I can only do so from where I sit and from where I am located (Monture-Angus, 1995). Through my sharing of who I am I establish the parameters of what I may know and not know. In doing so, readers can determine what fits for them and what doesn't. Before I send out this knowledge, I need to share a bit on where this knowing comes from and who I am to honor its' source and to be accountable. We arrive at our place of knowing because of our families, communities, Elders and many other helpers. Our knowledge bundles develop over time with experience, teachings, and reflections. Our genealogy of knowledge is significant and we acknowledge who our teachers are and where we received our teachings (Marsden, 2005). What follows is a brief introduction to who I am as a prelude and this is how we would traditionally begin.

First, in my language I announce my name, acknowledge my nation, relatives and family because they taught me about living on the land and life in the bush. Minogiizhigokwe n'dizhnakauz (I am Shining Day Woman). Anishinaabekwe n'dow (I am an Anishinaabe woman). Waubzhizhii n'dodem (I am Marten clan), and Flying Post n'doonjibaaam (I come from Flying Post First Nation). I am also Midewiwin and receive many of my teachings from the Three Fires Society Midewiwin Lodge. For the past twenty years I have a blended background of Indigenous based wholistic healing practices along with some western social work practice methods. Over the years many traditional mentors have appeared on my path and at the community level. My Anishinaabe relatives, Midewiwin and clan family continue to teach me to walk in the beauty of our culture and ways. Consequently, myknowledge bundle is both cultural Anishinaabe and western where I strive to balance both worlds. However, I have been actively focusing on my Anishinaabe culture and language which means learning my language, teachings, songs, ceremonies, medicines and many other aspects that our knowledge bundles entail. In part, my knowledge is a summation of those who have crossed my path and took pity on me enough to share their knowledge and wisdom. Finally, I am grateful for all the spirits that guide and walk with me. They provide the signs that let me know I am on the right path. Currently, I teach at Wilfrid Laurier University in an MSW Aboriginal Field of Study program where we employ wholistic knowledge and teachings on a daily basis. $\mathrm{We}^{2}$ call this process Indigegogy whereby we teach Indigenous theory and worldview using Indigenous pedagogy. Lester Rigney (1999) called an Indigenous methodology Indigenist, however in our Indigenous social work education context we call it Indigegogy. Finally, I come from the land and frequently return there as reference points for my work as 2 My colleague Malcolm Saulis tell us that the term was given to us by Stan Wilson who coined what we do as Indigegogy. 
an educator, researcher and practitioner. The teachings of the Anishinaabe inform my worldview.

\section{Indigenous wholistic theoretical orientation}

Indigenous wholistic theory is whole, ecological, cyclical and relational. The Medicine Wheel, Four Directions and Circles have been used as an effective and appropriate means and tools for develop healing strategies. They offer a multilevel strategy that is circular in nature which has been practised for thousands of years by our ancestors (Absolon, 1993; Graveline, 2004; Hart, 1996, 2002; Little Bear, 2000; Nabigon, 2006). The following diagram of concentric circles represents a level of being and illustrates the reciprocal interconnections of self, individual, family, community, nation, society and creation. At the centre is a tiny circle representing the Self. The next circle represents family, then the community, then the nation, society and outward to the ecology of creation. Inclusive to all the levels are the infants, youth, young adults, adults and Elders. Each level of being is affected by the historical, social, political and economic and each layer has a spiritual, emotional, mental and physical element. Indigenous wholism considers the connections and the

Diagram 1:

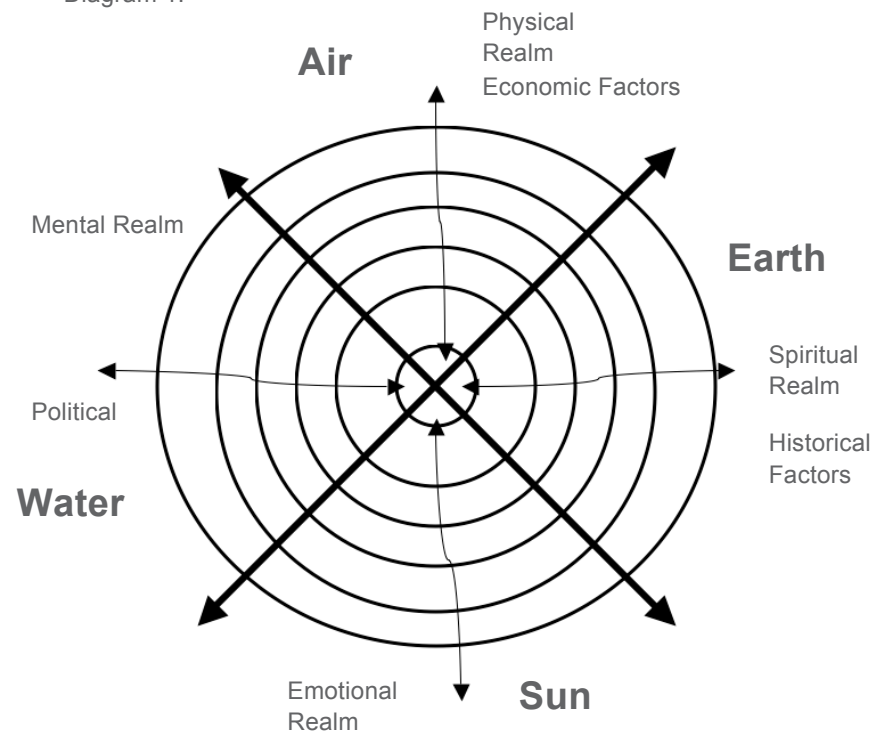

concept "we are all related" begins to make sense as we perceive each aspect in relation to the whole. The dynamics of our realities are created because of the relationships and experiences of these interrelationships and interconnections. I use the Medicine Wheel as a tool to depict Indigenous wholistic theory, which helps us to understand our realities and experiences by considering the influences of all elements of the whole on our individual and collective being. This is just a beginning.
Understanding Indigenous peoples experiences can initially be understood within such a wholistic framework. The above illustration illuminates that Indigenous peoples experiences can be framed and contextualized within a historical, social, political and economic framework. Such a wholistic framework provides a concrete tool toward understanding the nature of balance, harmony and 'Bimaadisiwin' - living a good life. It acknowledges the factors that contribute toward achieving that sense of peace and balance.

Imbalance is then determined to occur in the symptoms that people identify which are typically called presenting problems or issues. These presenting issues are initially identified by people, families or communities who desire a change toward peace and balance. Upon further consideration of the elements of Indigenous wholism in problem definition we need to consider factors that fuel imbalances among Indigenous peoples' lives. If Indigenous worldviews, traditions, values and beliefs are foundational to living a good life, then the absence or attack of Indigenous worldviews, traditions and identity has created imbalance and dis-ease. Colonizing agents and mechanisms of colonization such as residential schools, child welfare authorities, social welfare traps, land dispossessions etc... have all contributed to personal and familial imbalance in many areas of functioning (Duran \& Duran, 1995; Graveline, 2004; Hart, 2002; LaRoque, 1991; Nabigon, 2006). The attempted domestication ${ }^{3}$ of Indigenous peoples via Indian Act policies has contributed to disease and illness among the people. Now the internalization of colonialism contributes to internal violence and lateral oppression. As earth based and earth centred peoples, a forced disconnection from our land would naturally create imbalance and disease among the people. Our reactions to these conditions are then understandable. Indigenous peoples have been living and breathing oppressive conditions for centuries now and undoubtedly the internalization of racism and the need for community healing is apparent when,

Some of the greatest resistors to the recovery of Indigenous knowledge are our own Native people who have internalized the racism and now uncritically accept ideologies of the dominant culture... Because of the extent to which colonization has taken root, any efforts to restore our traditional ways would have to be matched with a strong community decolonization agenda. While developing a critical consciousness aimed at understanding precisely how colonialism has affected our health and mindset, and thus how we might meaningfully challenge that oppression, we can begin to reaffirm the richness and

3 I use the term domestication to coin what Paulo Freire in Pedagogy of the Oppressed describes when colonizing forces attempt to acculturate or assimilate Indigenous peoples. The treatment of Indigenous peoples by the colonizer with the goal of acculturation is akin to the domestication of animals. 
wisdom inherent in our traditional ways (Cavender Wilson, 2004, p. 72).

I agree with Angela Cavender Wilson in that using and applying Indigenous theory to practice requires a knowledge set of the social and political policies and practices. At this juncture, I become more specific in my presentation of Indigenous wholistic theory.
The following diagram is a more specific representation illustrating theoretical underpinnings using the four directions and spiritual, emotional, mental and physical elements. Within each element are some specific theoretical factors that warrant consideration in Indigenous based practice. There are many more elements and this representation is by no means exhaustive. Circle teachings are diverse and representations of such can look different depending on the context, teacher and Nation. With

NORTH

Diagram 2:

Giiwedin

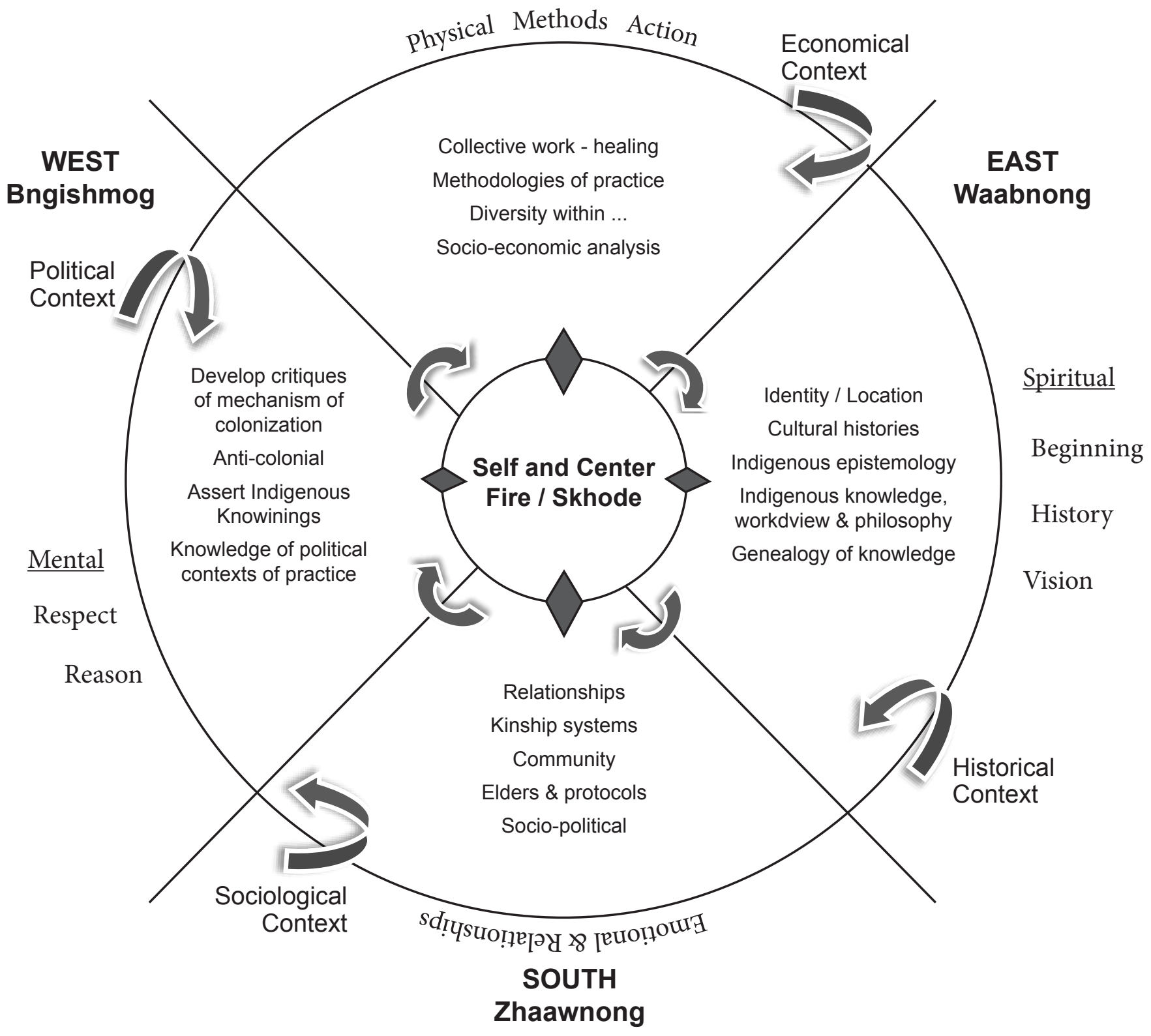


that being said, the proposed theoretical framework requires a dual knowledge set of Indigenous knowledge and anti-colonial knowledge. Current theory must tackle colonial constructs while asserting the power and role of Indigenous knowledge. The chapter is now organized using the following circle as a guide. Each direction is briefly introduced with teachings of the nature of that doorway or direction as given to me by my traditional teachers whom I am grateful to acknowledge (Herb Nabigon, Bawdwayidung, Obaunisay, Medwayaushii and many others). Grandfather Sun rises in the east and so we enter into this discussion through the eastern door and follow the directions to the south, west and north doorways. Each section will discuss components of Indigenous wholistic theory relative to each doorway. These directions are not mutually exclusive; in fact, they interrelate, interconnect and are interdependent. Any change or movement in one area will affect the whole. The arrows in the diagram illustrate the interrelationships and interdependence between all the components.

The discussion of each of the doorways is meant to guide a wholistic knowledge set. The goal of this article is to present an Indigenous wholistic theory for social work practice. It does not present the specifics of Indigenous issues or concerns, but presents a framework from which issues can be understood and practice guided. This article advocates a knowledge set that is based on the collective doorways of the whole circle - that is the knowledge set that an Indigenous wholistic theory commands.

\section{WAABINONG: In the East}

The teachings from the sacred direction of the eastern doorway, Waabinong, speak to us about new beginnings. The sun rises in the east presenting us with a new day of life. With each day we have new life and new gifts. Waabinong represents Springtime and rebirth. The Eastern doorway brings forth teachings of visioning, beginning and rebirth. Here is where I present literature that deals with foundational principles and issues. Visioning requires one to be able to see the past, the present, and envision the future. Visioning denotes the theoretical underpinnings and principles from which searching for knowledge begins. Beginning denotes recognition that Indigenous people are in a state of resurgence and revitalization and at this time in our long history we are recovering, reemerging, and reclaiming our knowledge base. The context of our past has vastly changed, yet we remain: We are Indigenous and we carry our ancestors' stories, teachings and knowledge. Renewal of this doorway gifts us with the ability to experience rebirth of the old into the new. In processes of renewal and rebirth change is inevitable.

Aspects of Indigenous wholism that proceed through the eastern doorway are spirit, identity and history. The role of spirituality must be considered within healing practices and processes (McCormick, 2005). Each and every being is a spirit being and acknowledging one's spirit begins with acknowledging oneself.Spiritual knowledge entails awareness and understanding of Aboriginal epistemology and a respectful consciousness of the sacred world to Indigenous peoples. Indigenous wholism implies a balance within all aspects and elements of the whole, which is achieved through interconnections, interdependence and interrelationships (Marsden, 2006). As Dawn Marsden states, "If we know who we are, that all life is connected through spirit, and if we learn how to live good lives, then by extension we will act responsibly toward the creation of harmonious and sustainable (healthy) relationships in this world" (Marsden, 2006).

Indigenous epistemologies, worldviews, methodologies and frameworks must form the basis for our knowledge quests and practice (Bishop, 1998; Cole, 2002; Duran \& Duran, 2000; Ermine, 1995; Fitznor, 2002; Kenny, 2000; Simpson, 2001; Sinclair, 2003; Wilson, 2001). Within the essence of Indigenous epistemology is spirituality and as Indigenous peoples our responsibilities include: To honor our relations with all of Creation; to follow our original instructions as orally passed on; to continually relearn ceremonies, rituals, daily protocols; to regenerate mutual relationships and not to replicate western paradigms (Cole, 2002; Ermine, 1995). Spiritual considerations occur within the guidelines and frameworks of our Creator and we are to honor the knowledge we have. Spirituality is inherent in Indigenous epistemology, which sees everything in relation to Creation, the earth and recognizes that all life has spirit and is sacred. Willie Ermine (1995) talks about the inner space and inner knowing within Aboriginal epistemology. He identifies the ways inner knowing is inherent in Aboriginal epistemology in the following quote.

Those who seek to understand the reality of existence and harmony with the environment by turning inward have a different, incorporeal knowledge paradigm that might be termed Aboriginal epistemology. Aboriginal people have the responsibility and birthright to take and develop an epistemology congruent with holism and the beneficial transformation of total human knowledge. The way to this affirmation is through our own Aboriginal sources (Ermine, 1995, p. 103).

The doorway to the inner space, where the ancestral knowledge sits, is through other realms via dreams, ceremonies, vision quests and rituals. The ancestors are there waiting to share their knowledge. The map to get there isin Indigenousknowledge and more specifically within Aboriginal epistemology. The published work of Indigenous scholars reveals that Indigenous worldviews and ancestral knowledge are being carried forward 
into our future by asserting the role of Indigenous cultural knowledge and history and second by critiquing and dismantling colonizing knowledge and mechanisms of oppression. These actions set the stage for visioning, beginning and renewal. Out of renewal emerges a duality of knowledge, characterizing a cultural discourse and a colonial discourse. Both must necessarily be addressed.

Within an Indigenous worldview, we believe we are Spirit beings. As such, identifying who we are is the first protocol we do before we begin any ceremony, speak or act. Some people announce their Spirit names as they address the Spirit. Some people announce their English name, clan and Nation. We speak from our location and announce who we are, where we come from and what our intentions are. In doing so, we are also announcing who we are not and where we do not speak from. Accountability and ethics of oral tradition is thus established and the people now have the power and choice to receive your words or actions. Within this specific doorway Indigenous wholism implies that we attend to our positionality and locate ourselves (Absolon \& Willett, 2005; Monture-Angus, 1995). Inclusive to location and positionality is identifying who you are, where you come from and what your motives or intentions.

Waabinong, in the east, also implies knowing our history: cultural and colonial. It calls upon a knowledge base of: the history of colonization of Indigenous peoples in Canada and its impact on Indigenous peoples' cultures and traditions; the oppression of Indigenous spirituality, ceremonies, songs, dances, gatherings, naming and death ceremonies, and life teachings. It calls for us to know that the suppression of Indigenous people's bundles and their "traditional Elders, keepers of knowledge were deliberately murdered” (Colorado, 1988, p. 51). Sacred birch bark scrolls, knowledge bundles and ceremonial objects were confiscated, destroyed and outlawed. To understand the extent of Indigenous peoples anger, grief, depression and loss one must develop an awareness and understanding of the impact of having ones culture, family, children, language and way of life attacked over and over.

Indigenous scholars are calling for an ongoing critique and deconstruction of colonial motives, theories and methods (Absolon \& Herbert, 1997; Duran \& Duran, 1995, 2000; Henderson, 2000b; LaRocque, 1991; Ross, 2005; Smith, 2000; Talbot, 2002). Critical reflections and discourse set a pathway for decolonization and for freedom to be attained without replicating or empowering colonialism and Eurocentric hegemony (Alfred, 2005). Decolonization presupposes a commitment to a critical analysis of the existing unequal power structures, a rejection of hegemonic belittling, and a commitment to consciousness raising and politicization. Clearing the mind of colonial constructs alone is not enough. Decolonization is the common descriptor for unlearning out of racism and colonization (Calliou, 2001; Fitznor, 2002; Graveline, 2004; Simpson, 2001; Wa Thiong'o, 1986).

In summary, the theoretical elements of Indigenous wholistic theory of Waabinong, the Eastern doorway are Spirit, beginnings and history. Some key points from this doorway are:

- Beginning and rebirth

- Inclusion and respectful acknowledgement of Spirit

- Spirituality is connected to healing

- Establish your location and position yourself within your practice as such

- Acknowledge your genealogy of knowledge

- Recognize the legitimacy of Indigenous epistemologies, worldviews and knowledge

- Understand that Indigenous peoples have a culture history that predates colonization.

- Identity: Understand the diversity within families, individuals \& communities

- Develop a knowledge set about the history of colonization and the mechanisms of oppression.

\section{ZHAAWNONG: In the South}

The Southern doorway, Zhaawnong, encompasses the emotional and relational realms. It brings forth teachings of life, relationships, people and growth and will cover literature relating to principles of reciprocity and relationships. Zhaawnong brings the summer and renewal. This doorway addresses issues of relationships, protocols, accountability, reciprocity and community. Relationships can extend to humans, the natural and spiritual world. For example, "Indigenous peoples the world over follow the rhythm of the cosmos with distinct relationships to the sun, moon, stars, animals, plants, sound, wind, water, electrical and vibrational energy, thunder, lightning, rain, all creatures of the land and water, the air, and the rhythm of the land itself" (Solomon \& Wane, 2005, p. 55). In Indigenous contexts building and nurturing quality relations is integral to living in a good way.

Kinship systems and their relationship connections are recognized in the southern doorway. Leroy Little Bear (2000) identifies the value of knowing that totality and wholeness exist within the circle of kinship. He uses an analogy of four flower petals to symbolize strength, sharing, honesty and kindness in kinship relations. Further, he states that "the function of Aboriginal values is to maintain the relationships that hold creation together. If creation manifests itself in terms of cyclical patterns and repetitions, then the maintenance and renewal of those patterns is all-important" (Little Bear, 2000, p. 81). 
Kinship systems serve to connect threads between individuals, families and communities and extend beyond biology. For example, kinship systems can be based on the clan system where relationships and roles are determined by clan identity and function (Benton-Banai, 1988). Families have tendencies to adopt people and community members can relate to each other as aunties, uncles, nieces, nephews, brothers or sisters without the genetic basis for such ties. Our Cocomish and Shaumish can be other Elders other than our biological ones. Families and communities are broadly defined and are not limited to genealogy or genetics.

Indigenous communities have immense strength and resources from which kinship ties, healing and recovery, wellness, survival and collectivity exist. The viability of community relationships in social work practice cannot be underestimated. Identifying community strengths in all areas of prevention, intervention, rehabilitation, support and postvention approaches will contribute to the development of grass roots, community strengths approaches (Gone, 2004). Principles of collaboration and empowerment ought to guide relationships with community members such as engaging with local community members in the planning and delivery of service. From an Indigenous perspective the culture of a community is where the heartbeat of that nation resides. Communities are suffering in the colonial aftermath, hence their heartbeats may be weak. Nevertheless, the heartbeat of a community is in the people, which ought to influence methods of practice. Community interests ought to be considered essential elements of practice and community involvement fostered at all levels of service delivery such as planning, visioning, brainstorming, designing, creating, evaluating, assessing, intervening and treating. In this sense, methodologies of practice will diversify as community contexts vary from one community to the next. Training for work with Indigenous communities ought to be interdisciplinary and diverse community based methodologies encouraged. Methods that foster community relationships and collaborative processes include the teachings of the Medicine Wheel, storytelling, sharing and teaching circles, community participation and role modeling (Poonwassie \& Charter, 2001). Methods of practice ought to attend to supporting and fostering healing relationships within self, family and community.

Elders are another cornerstone of Indigenous knowledge, culture and heritage. Oral traditions, languages and historical accounts would be lost without the wisdom, knowledge and experience of Elders. Ethics of practice exist in the protocols in working with the Elders and with traditional knowledge. Elder protocols are varied depending on the nation and territory and identifying reliable Elders will occur in consultation and communication with community resource people. For example, some people will offer tobacco, cloth or a small gift as a gesture of reciprocity and gratitude. Elders are essential to learning and teaching through mechanisms such as storytelling, ceremony, songs, dances, and passing on teachings. Healing and wellness programs often employ Elders to work with children, youth and families. Community initiatives in Ontario such as Enaahtig Healing Lodge and Learning Centre, Kii-Kee-Wan-Nii-Kaan Southwest Regional Healing Lodge, Anishinaabe Health in Toronto, Shawanaga Healing Centre, and Skaagamakwe Healing Centre work with Elders in the delivery of programs and services. There are many other examples across the country of programs and services that recognize the role and contribution that Elders can make to healing and wellness initiatives.

This doorway also calls for the development of a critical understanding of the social context and conditions of issues such as an understanding of family violence and abuse, alcoholism, addictions, depression, grief and loss, disempowerment, suicide, intergenerational trauma, lateral violence, and multigenerational trauma. Angela Cavender Wilson states that:

When considering the phlethora of social problems facing Indigenous communities today (including poverty, chemical dependency, depression, suicide, family violence, and disease), it is profoundly clear that these are the devastating consequences of conquest and colonization. For Indigenous nations, these problems were largely absent prior to European and American invasion and destruction of everything to us. A reaffirmation of Indigenous epistemological and ontological foundations, then, in contemporary times offers a central form of resistance to the colonial forces that have consistently and methodically denigrated and silenced them (Cavender Wilson, 2004, p. 70).

I believe that when practitioners continue to apply psychotherapeutic approaches to practice that omit the social and political contexts of Indigenous peoples realities than their practice continues to pathologize, diminish and problematize Indigenous peoples. I agree with Eduardo and Bonnie Duran (1995) that the DSM ought to have a category recognizing the post trauma affects of colonization and genocide. Further, "those negative influences have resulted in the marginalization and clientization of these groups in contemporary society" (Poonwassie \& Charter, 2001, p. 64). We must be careful to not adopt theories and methods of practice that only pathologize and problematize Indigenous clients without regard for the broader socio-political issues and historical context.

In summary, the theoretical elements of Indigenous wholistic theory of Zhaawnong, the Southern doorway acknowledge the emotional aspects of the whole where relationships and sociological contexts are understood. This doorway specifically: 
- Calls for renewal at relational levels

- Attends to relationships

- Integrates understandings of diverse relationships

- Understands kinship systems as moving beyond genetics

- Identifies community strengths and resources,

- Collaborates with community to foster healing relationships

- Utilizes methods that support healthy relationship building

- Acknowledges the role and contribution of Elders and protocols and

- Contextualizes issues within a socio-political analysis of social problems facing Indigenous peoples today.

\section{NIINGAABII'ONG: In the West}

The Western doorway, Niingaabiiong, brings forth teachings of the ancestors, the mind and respect. It relates to respect of knowledge and knowledge of creation. Niingaabiiong brings the Autumn and cleansing. It also calls for mental strength and reason. Operationalizing respect in practice requires one to step back and think wholistically and consider how all the doorways specify and articulate the value of respect. Asserting Indigenous knowledge as a tool for recovery from colonial trauma and all its manifestations is acknowledged in this doorway. It is evident that in Indigenous communities across the land, a re-emergence of knowledge is occurring. Decolonizing our minds in addition to establishing a critical discourse, theory and practice based on Indigenous knowledge are acknowledged by Niingaabiiong.

Respect is a core principle from which Indigenous methodologies ought to emerge (Absolon \& Willett, 2004; Archibald, 1993; Battiste \& Henderson, 2000a; Fitznor, 1998; Graveline, 2000; Gross, 2002; Kenny, 2000; McPherson \& Rabb, 2001; Sinclair, 2003; Wilson, 2003). Respect is a wholistic value and can be applied and operationalized at all levels of social work practice. To acknowledge and validate Indigenous philosophies and worldviews is to practice respect. Gross (2002) states that respect is in the Anishinaabe teachings of Bimaadziwin, which loosely translates to mean 'a good life'. The life goal of the old Anishinaabe was to follow the Anishinaabe teachings of Bimaadziwin, hence to strive toward living a good life. We need to learn our teachings and apply these teachings today to rebuild and recover from colonial trauma. I have heard over and over how Indigenous people have been helped through our own cultural mechanisms such as sweat lodge ceremonies, healing ceremonies, sharing and talking circles, dances, songs and other cultural pathways to wellness. Indigenous ways of health and recovery remind people of the beauty of who we are, where we come from and what we know. It builds healthy esteem and confidence in our identity. It instills good feelings about being Indigenous again and reconnects people to the power of their identity. We must respect who we are, what we know and where we come from. Our recovery and rediscovery is imperative to our healing as a peoples.

The recovery of traditional knowledge is deeply intertwined with the process of decolonization because for many of us it is only through a consciously critical assessment of how the historical process of colonization has systemically devalued our Indigenous ways that we can begin to reverse the damage wrought from those assaults. (Cavender Wilson, 2004, p. 72)

Respect calls upon us to look again, speculate, consider and operationalize Indigenous knowledge as a source of healing and recovery. In itself, though, Indigenous knowledge is massive, complex and dynamic. Many of Indigenous scholars share commonalities across the diversity of their nations regarding Indigenous knowledge (Absolon, 1993; Battiste \& Henderson, 2000b; Benton-Banai, 1988; Brant Castellano, 2000; Cajete, 2000; Colorado, 1988; Fitznor, 1998; Graveline, 2000; Gunn Allen, 1986, 1991; Hart, 2002; Henderson, 2000a; Holmes, 2000; Kovach, 2005; Martin, 2002; Nabigon, 2006; Thomas, 2005). "There is a communal ideology and unique worldview between and among the Indigenous peoples of the world. This common thread is inherent in most indigenous cultures despite the severity and sustained duration of the colonial impact ..." (Solomon \& Wane, 2005, p. 54). For example, Indigenous knowledge is consistently referred to as wholistic. That is a given. Additionally, "most Aboriginal worldviews and languages are formulated by experiencing an ecosystem" (Henderson, 2000a, p. 259). Indigenous worldviews teach people to see themselves humbly within a larger web or circle of life. It is both feminine and masculine and acknowledges the roles of both men and women. The Earth is feminine and the Sun is masculine - both are necessary for life to exist. Men's work and women's work may be different, but they are interdependent and contribute to a healthy whole. Interrelationships and interdependence within this circle create a consciousness of relationality within all of creation.

Indigenous knowledge comes from ancestral teachings that are spiritual and sacred in origin (Ermine, 1995). It exists in our visions, dreams, ceremonies, songs, dances, and prayers. It is not knowledge that comes solely from books. It is lived knowledge, experiential knowledge and enacted knowledge. It is cyclical and circular, and follows the natural laws of creation. Indigenous knowledge is earth centered with ecology-based philosophies derived out of respect for the harmony and balance within all living beings of creation. Indigenous knowledge occupied itself with the past, present and future. The past guides our present and in our present we must consider the generations to come. Indigenous 
knowledge lies in our stories and narratives and within our oral traditions. It exists in our relationships to one another and to all of creation. Indigenous knowledge exists in the animals, birds, land, plants, trees and creation. Relationships among family and kinship systems exist within human, spiritual, plant, and animal realms. Indigenous knowledge systems consider all directions of life: east, south, west, north, beneath, above and ground levels. Life is considered sacred and all life forms are considered to have a spirit. We manifest this knowledge in our humility in offering thanks for life and in seeking life's direction. Indigenous knowledge has enabled Indigenous nations to live in harmony and balance with the earth, without harm. Our ancestors have used their knowledge to respect the laws of creation, while subsisting on the land, since time immemorial. Thus, practice that is derived from Indigenous knowledge would certainly entail methods that demonstrate respect and reverence within these understandings. Healing centers today, for example, have programs and services reconnecting people to the land, plants, medicines and elements. Youth programs venture outdoors where the natural world fosters and participates in the healing and recovery needs of young adults. Sitting by a fire is peaceful and water fosters a sense of serenity and calmness. Earth's elements are healing elements too.

Our ancestors sit in the Western doorway and when we use spiritual protocols in our practices we are sending our thoughts into the spirit world. The significance of ancestors cannot be ignored. Many Indigenous people pay homage to the ancestors and turn to sacred ceremonies to tap into and seek out ancestral knowledge. Healers and medicine keepers work with healing ceremonies and invoke the ancestors and use of sacred medicines to facilitate healing practices. Recognition of the ancestors implies an acknowledgement of the cycles of life and death as natural life cycles. Funerals and burials involve teachings of life and death, which facilitates the grieving process for family and community. Indigenous communities have high incidences of death and loss and our capacity to cope and survive such tremendous losses is fostered through our ceremonies and cultural understandings of life and death. Death and dying, grief and loss are among common issues that confront Indigenous people. Higher mortality rates plague Indigenous communities and depression is often connected to unresolved grief and trauma. Loss has been felt with loss of people and family members, loss of language, culture, land, freedom, movement, subsistence and livelihood. The losses are many and are vitally important when considering issues of unresolved grief and loss. Importantly though, Indigenous theory has teachings which reflect understandings of life and death.

In contextualizing the loss of culture, language, traditions, community, land, and family this doorway casts our attention toward the political arena to further develop an understanding of the politics of colonization and its impact on Indigeniety, governance, livelihood, subsistence, freedom, land bases, and living an Indigenous way of life. The extent to which assimilation policies and oppressive tactics diminished Indigenous peoples good life cannot be underestimated historically and currently. We need to have a political analysis to understand why families do not know their life cycle ceremonies or why children were forced to attend residential schools. We need to understand the lack of choice and free will and forced erosion of the culture and language so that we do not perpetuate a 'blaming the victim' stance in our practice. For example, while working at the community level, I recall people blaming members in their own community and negatively labeling them 'Bill C-3lers'. Their remarks indicated that they thought 'Bill C-3lers' were undeserving of their membership, housing and treaty entitlements. Consequently, I engaged them in critical education about the nature of Bill C-31 (an Indian Act amendment) and the history of the Indian Act and sexism instituted in it. Many of our people don't have this knowledge set and so Indigenous wholistic theory calls for practitioners to become critically literate and critical educators to their clients to begin teaching individuals, families and communities about the colonization of Indigenous peoples on their own land. We must develop anticolonial practices and consider issues of power and oppression in areas of health, social welfare, child welfare, justice, mental health, family and community services. In this sense, this doorway calls for a power analysis and an understanding of power and social constructions of health and illness.

In summary, the theoretical elements of Indigenous wholistic theory of Niingaabiiong, the Western doorway acknowledge the mental aspects of the whole where reason and respect are addressed. This doorway specifically:

- Recognizes ancestors, ancestral knowledge and power

- Acknowledge the mental aspects and power of knowledge

- Asserts and respects Indigenous knowledge and ways of knowing

- Applies a critical analysis and knowledge of the political contexts of practice

- Develops critiques of the mechanisms of colonialism and engages in critical literacy and critical education with Indigenous communities

- Is anti-colonial in practice and works to counter colonial ideologies

- Acknowledges the ancestors and cycles of life and death

\section{GIIWEDINONG: In the North}

The Northern doorway, Giiwedinong, brings forth teachings of healing, doing and movement. In this realm the 
physical elements are acknowledged and physical action and movement are located. Giiwedinong brings the Winter and healing. When all the other three directions are in place, the teachings of the Northern doorway are operationalized and it is with consciousness of all the doorways that action occurs in a conscious and healing way. Methods of practice are recognized in this doorway as 'doing. As an example, I suggest the reader locate a recent publication edited by Raven Sinclair, Michael Hart and Gord Bruyere entitled Wicihitowin Aboriginal Social Work in Canada (2009), which provides many excellent contextual chapters on Indigenous based social work practice. What we do is addressed in the northern doorway and winds of change gift us with opportunities to heal. In practice, the following quote poses good questions for consideration when bringing forth healing practices.

\section{In many Indigenous societies some of the questions they are constantly asking are, How much of the sacred healing practices can they share? Would these practices work out of context? Is it possible to re-create rituals of healing outside of the healers' community? Each healing practice is unique to the individual requiring healing and to the healer. (Solomon \& Wane, 2005, p. 53)}

Some people will not discuss or share sacred healing practices, but there are now common practices among Indigenous peoples that are readily identified. Indigenous based practices ought to recognize the disconnection that colonial mechanism created and engage to reconnect people through collective processes. Circle processes or circle talk was named as a viable methods for working with Indigenous groups and communities (Graveline, 2000; Hart, 1996; Steinhauser, 2001; TeHennepe, 1997; Weenie, 1998). I agree that, "[m]any indigenes have growing interest in returning to their sacred teachings and ceremonies and will continue to follow their traditions to sustain themselves and to help the generations to come" (Solomon \& Wane, 2005, p. 53). 'Protocols', 'circles', and 'sharing' are common Indigenous practices that bring people together for sharing, learning and healing. Circles processes counter the isolation and alienation that many Indigenous people experience in relation to the issues and concerns they face. Sometimes we don't know what we don't know until exposed to knowledge and experiences of others. Only when fed with accurate information can we develop in our understanding and knowledge. The following story was told to me by one of my mentors and has helped create an understanding of patience and care within the healing journey:

Once there was a starving human without food or water, alone on a raft for a long, long time - salt water surrounded the raft and was undrinkable. More time passed and this person is one day discovered by another human who is able to recognize the thirst and hunger and not be afraid of it. This human offers the diseased, sickly and starving person a dropper of water - not a whole meal but only a slight drop of water. Slowly the human absorbs the drop and then is given another drop. A few drops of water turn into a dropper of water over time. The dropper of water is tolerable and digestible; a full meal would not be. In time, that dehydrated person is able to drink more and more and more. And over time this human begins to acquire an appetite and over time develops an incredible hunger and yearning to be fed: the dropper is no longer enough. The hunger and yearning become the drive for more food... and is ready to digest food...

Learning about our truths and sharing collective pains is a process that occurs in time. Sitting in many sacred circles (women's circles and mixed gender circles), through listening and listening, and sharing and dialoguing as we fed each other droppers of water taught me about patience and acceptance. Our thirst and yearning for knowledge is quenched through the listening to others' stories and experiences and drawing on our collective strengths. Acquiring the knowledge and understanding is a life long journey and circle processes provide a culturally congruent means. Our feast therefore is a series of "droppers of water" through conversations and dialogues, and not the eating of one large meal. Healing is fostered, friendships develop and relationships between the people are restored. Within the circle process many formats have been shared in terms of amount of people and length. Michael Hart (2002) has researched and worked with circles for many years and his book Seeking Minopimatisiwin is a good resource. Additionally, I would add that methods of gathering people together are varied, but one thing for sure is that food is central to any successful gathering. Feeding people in a loving and good way will fuel a positive environment and nurture optimistic feelings. Rod McCormick (2005) presents a worthy chapter where Indigenous practices toward a healing path are summarized. He identifies the healing path and outlines the role of "spirituality in healing, the role of nature, the role of cleansing, the role of culture in healing, the model of the circle and Medicine Wheel, the concept of balance, the role of connection, and the role of ceremony in healing" (p. 293-294). It explains healing approaches and practices that utilize Indigenous methods while integrating concepts such as connection, balance, nature and wholism. His chapter is useful because he links these approaches to counselling and therapy with individuals, groups and communities. Indigenous healing processes are identified as wholistic, multifaceted and diverse where sharing is facilitated in through a variety of paths.

I had the privilege, at a young age, of being a student of traditional teachers and was given teachings to live, practice 
and share. I also had the privilege of growing up in the bush. I acknowledge these privileges because of the institutional racism that severed many First Nations' from their inherent right to the traditions and values of our many cultures. All Indigenous people, I believe should have their teachings with them. My responsibility has been to internalize the teachings into who I am and honour them in the way I live. I cannot lose them or have them stolen - they exist as a part of me - in my mind, my body and my spirit and heart. For these tremendous gifts I am most grateful. Relearning the cultural teachings, worldview and philosophies of my people has been my personal and professional methodology of practice. Committing to relearning our culture and language as a methodology for emancipatory and liberating practice is now essential to my life and work. If I am able to offer Indigenous people something, I want it to be based within Anishinaabe epistemology.

Diversity is another concept of this doorway and actions of practice ought to reflect the diverse manifestations of colonialism and internalized colonialism. People have diverse experiences and not all Indigenous people aspire to be traditional or have traditional knowledge. Indigenous people are also Christian and traditional or neither. Some people are assimilated into Canadian society and like it that way. Indigenous people are diverse in their linguistics, lifestyles, culture and way of life. Families are diverse and communities are diverse. Community governance structures can be diverse and the operations of programs may reflect cultural and organizational diversity. Communities may vary in their priorities, goals and objectives. Land bases are diverse and livelihoods will also be diverse. Nations across Canada are very diverse as are the linguistic groupings. Programming that might work in one community may not be appropriate for another because of the unique conditions and situations that exist within communities. Distinct community based strategies will require specific considerations relative to each community.

Additionally, economic conditions among Indigenous people are diverse, though there is a prevalence of poverty and low socio-economic status. The high incidences of unemployment and the poor housing conditions continue (Wesley-Esquimaux \& Smolewski, 2004). Some communities struggle with poor qualities of drinking water and sewage systems. The physical conditions under which some Indigenous people exist are deplorable. A socio economic analysis of poverty, unemployment, housing, homelessness and other consequences of the economic marginalization of a peoples in a colonial and racist society is required to refute any notion that Indigenous people are poor because of stereotypical notions of being lazy, drunk or stupid. One need only look at the peasant farming policies in the prairies in the late 1800's to realize the governments agenda was to maintain Indigenous people as the working poor and did so by creating glass ceilings on profit margins in farming (Carter, 1990). Because of racism, oppressive Federal policies, fiscal erosions, and reneging on fiduciary responsibilities, Indigenous people have retained sub-standard economic status. Understanding the economics of Indigenous peoples lives requires a structural economic analysis. This understanding will foster a compassionate lens from which you perceive the people and their conditions. I believe this analysis prevents a blaming the victim and redirects the problem to the institutions and structures.

In summary, the theoretical elements of Indigenous wholistic theory of Giiwedinong, the Northern doorway acknowledge the physical aspects of the whole where methods of practice and action are. This doorway specifically:

- Recognizes the healing in being and doing

- Calls for action and movement

- Acknowledges the collective work

- Addresses methodologies of practice from Indigenous frameworks such as sharing or teaching circles, ceremonies, use of nature, and process oriented action

- Healing as a restoration of balance using tools such as the Medicine Wheel

- The diversity within Indigenous contexts

- Encourages a socio-economic analysis to contemporary conditions

\section{CENTER SHKODE}

The center shkode (fire) is where the fire exists and where all four doorways intersect and interrelate. The center is where balance and harmony exist when all aspects are living in harmony and balance. The center fire could also represent Self in relation to all else. It is the essence of self and the manifestation of the whole. In summary, the Center Fire represents a coming together of all four directions and Willie Ermine (1995) tells us more about this center fire of the Self:
Aboriginal epistemology is grounded in the self, the spirit, the unknown. Understanding of the universe must be grounded in the spirit. Knowledge must be sought through the stream of the inner space in unison with all instruments of knowing and conditions that make individuals receptive to knowing. Ultimately it was in the self that Aboriginal people discovered great resources for coming to grips with life's mysteries. It was in the self that the richest source of information could be found by delving into the metaphysical and the nature and origin of knowledge. Aboriginal epistemology speaks of pondering great mysteries that lie not further than the self. (p. 108) 
The center represents the fire of life where all directions meet and locates the teachings of integration, balance, interconnections, and holism. The center also represents the Self - the essence of the cumulative aspects of self: the spirit, heart, mind and body. Utilizing a wholistic analysis enables practitioners to better understand people in their whole context as the center really represents the cumulative aspects of all four doorways.

Each doorway in isolation from the others is insufficient. All doorways are interdependent, interconnected and make up the collective whole. An Indigenous wholistic theory of practice considers all four doorways and their elements. For example, an Indigenous worldview effects how people see themselves in relation to their community and themselves. Recognizing cultural knowledge implies the existence of methods of healing and practice that have been exercised and applied in Indigenous contexts. Wholistic practice means to honour the balance and respect all the directions in programming, policy and practice. For example: create programs that feed the spirit (using medicines of sweetgrass, sage, tobacco and cedar; ceremonies and circle format), the emotions (the internalized inferiority, fear, shame, anger, pain and self-hate), the mind (educating First Nations workers and shareholders ${ }^{4}$ about the authentic history, the nature of their own experience, decolonizing our minds and unlearning racism, and dealing with our internalized racism and inferiority), and the body (addressing the symptoms of racism that First Nations people, workers and leaders carry with them as baggage that result in low self-esteem, substance and personal abuse, family violence and suicide).

Indigenous knowledge is a lived knowledge meaning that you must practice what you know and be what you do. There is no distinction between living and working. Indigenous knowledge is a way of life. For Indigenous helpers to continue to develop their knowledge and understanding into practice they must be provided with opportunities to learn. Professional development for Indigenous helpers means those helpers need to be supported to attend ceremonies and traditional venues so they can learn how to pick up their knowledge bundles. Traditional knowledge is transmitted and passed on at ceremonies and that is where we learn the teachings and protocols.

Workers need to be aware of Indigenous peoples' contexts and within Indigenous contexts is where capacity is developed. Community based education directed at capacity building and critical education fosters peoples' abilities to control their own needs and program directions. Building a solid foundation for 4 I learnt of this term at Kii-Kee-Wan-Nii-Kaan Healing Lodge where the term shareholder was used in lieu of client as shareholders indicated that people have a stake \& investment in their own wellness where their wellness journey is a mutual process. I liked the application of the term shareholder.

(C) Kathy Absolon any initiative is paramount to its success. Any community based initiative ought to have an anti-colonial agenda coupled with an affirmation and presence of Indigenous ways of knowing, being and doing. Staff education will, in part, address an authentic movement of healing and will begin to truly reflect Indigenous wholism in practice. Professional development is also about cultural development and a commitment to providing cultural teachings and language lessons empowers helpers in their own identity and knowledge set. In essence, practice and programming based on Indigenous theory ought to support workers to be strong and healthy in terms of clear minds, strong spirits, healthy bodies and healing hearts. A genuine and real movement addresses and deals with the internalized oppression of First Nations peoples. It also includes and addresses symbolic components of culture and spirituality in a complementary fashion and in way that strengthens and heals our spirit, bodies, and heart.

This article was set forth to present an Indigenous wholistic theory as a knowledge set for practice. I utilized the concepts of concentric circles and four directions. As I travelled around the circle I discussed some elements related to each direction eventually leading to the place where all components intersect. Indigenous wholistic theory is cyclical, circular and wholistic. Oral traditions were typically the venue for transmitting such knowledge. Utilizing visuals is one method to try to lift the words and concepts off the page. Ironically, Indigenous theory is not something one can acquire vicariously or by reading a book. It is a living phenomenon. This representation of Indigenous wholistic theory can be elaborated upon much further. My hope is to convey a theory that is based on the culture and traditions of Indigenous worldviews; is anti-colonial in its perspective; is wholistic and cyclical; and is ecologically derived. Spiritual and natural laws direct the protocols from which these methodologies are derived. Understanding and learning Indigenous wholistic theory is simultaneously simple and complex. It is both fluid and concrete. B'maadisiwin is the good life we strive for and the Creator gave us all that we need to heal ourselves wholistically. Indigenous ways of knowing, being and doing have worked for our ancestors and can be translated into contemporary contexts. Our nations are not bankrupt. We have the spirit of our ancestors and strength of knowledge and theory that has a capability to heal ourselves, our families, our communities, nations and the earth. Indigenous wholistic theory is a theory for balance, harmony and B'maadisiwin. Chi'miigwech. All my relations!

\section{References}

Absolon, K. (1993). Healing as practice: Teachings from the medicine wheel. Unpublished paper prepared for the Wunska Network. 


\section{Indigenous Wholistic Theory: A Knowledge Set for Practice}

Absolon, K., \& Herbert, E. (1997). Community action as a practice of freedom: A First Nations perspective. In B. Wharf \& M. Clague (Eds.), Community Organizing, Canadian Experiences (pp. 205-227). Toronto: Oxford University Press.

Absolon, K., \& Willett, C. (2004). Aboriginal research: Berry picking and hunting in the 21 st century. First Peoples Child \& Family Review, 1(1), 5-18.

Absolon, K., \& Willett, C. (2005). Putting ourselves forward: Location in Aboriginal research methodology. In L. Brown \& S. Strega (Eds.), Research as resistance: Critical, Indigenous and anti-oppressive research approaches. Toronto: Canadian Scholars Press.

Alfred, T. (2005). Wasase: Indigenous pathways of action and freedom Peterborough: Broadview Press.

Archibald, J. (1993). Researching with mutual respect. Canadian Journal of Native Education, 20(2), 189-192.

Battiste, M., \& Henderson, J. Y. (2000a). Ethical issues in research. In Protecting Indigenous knowledge and heritage (pp. 132-144). Saskatoon: Purich Publishing Ltd.

Battiste, M., \& Henderson, J. Y. (2000b). Protecting Indigenous knowledge and heritage: A global challenge. Saskatoon, SK: Purich.

Benton-Banai, E. (1988). The Mishomis book. Hayward, Wisconsin: Indian Country Communications Inc.

Bishop, R. (1998). Freeing ourselves from neo-colonial domination in research: a Maori approach to creating knowledge. Qualitative Studies in Education, 11(2), 199-219.

Brant Castellano, M. (2000). Updating Aboriginal traditions of knowledge. In G. Dei, J.S., B. L. Hall \& D. G. Rosenberg (Eds.), Indigenous knowledges in global contexts: Multiple readings of our world (pp. 21-36). Toronto: University of Toronto.

Cajete, G. (2000). Indigenous knowledge: The Pueblo metaphor of Indigenous education. In M. Battiste (Ed.), Reclaiming Indigenous voice and vision (pp. 181-191). Vancouver, BC: UBC Press.

Calliou, S. (2001). Decolonozing the mind: A non-empirical reflection of some First Nations scholarship. In K. P. Binda \& S. Calliou (Eds.), Aboriginal education in Canada: A study in decolonization (pp. 195-210). Mississauga Ontario: Canadian Educators' Press.

Carter, S. (1990). Lost Harvests. Montreal \& Kingston: McGill-Queen's University Press.

Cavender Wilson, A. (2004). Reclaiming our humanity: Decolonization and the recovery of Indigenous knowledge. In D. A. Mihesuah \& A. Cavender Wilson (Eds.), Indigenizing the academy. Transforming scholarship and empowering communities (pp. 69-87). Lincoln: University of Nebraska Press.

Cole, P. (2002). Aboriginalizing methodology: Considering the canoe International Journal of Qualitative Studies in Education, 15(4), 447-460.

Colorado, P. (1988). Bridging Native and western science. Convergence, XXI $(2 / 3), 49-68$.

Duran, B., \& Duran, E. (1995). Native American postcolonial psychology. Albany, NY: State University of New York Press.

Duran, B., \& Duran, E. (2000). Applied postcolonial clinical and research strategies. In M. Battiste (Ed.), Reclaiming indigenous voice and vision (pp. 86-100). Vancouver: UBC Press.
Ermine, W. (1995). Aboriginal epistemology. In M. Battiste \& J. Barman (Eds.), First Nations education in Canada: The circle unfolds (pp. 101-112). Vancouver: UBC Press.

Fitznor, L. (1998). The circle of life: Affirming Aboriginal philosophies in everyday living. In D. C. McCance (Ed.), Life ethics in world religions (pp. 21-40). Atlanta, Georgia: Scholars Press.

Fitznor, L. (2002). Aboriginal educators' stories: Rekindling Aboriginal worldviews. Ontario Institute for Studies in Education of the University of Toronto, Toronto.

Freire, P. (1996). Pedagogy of the oppressed. Twentieth anniversary edition. New York: Continuum.

Gone, J. P. (2004). Keeping culture in mind. Transforming academic training in professional psychology for Indian country. In D. A. Mihesuah \& A. Cavender Wilson (Eds.), Indigenizing the academy. Transforming scholarship and empowering communities (pp. 124-140). Lincoln: University of Nebraska Press.

Graveline, F. J. (2000). Circle as methodology: enacting an Aboriginal paradigm. Qualitative Studies in Education, 13(4), 361-370.

Graveline, F.J. (2004). Healing wounded hearts. Halifax: Fernwood Publishing.

Gross, L. W. (2002). Bimaadiziwin, or the "Good Life," as a unifying concept of Anishinabe religion. American Indian Culture and Research Journal, 21(1), 15-32.

Gunn Allen, P. (1986). The sacred hoop: Recovering the feminine in American Indian traditions. Boston: Beacon.

Gunn Allen, P. (1991). Grandmothers of the light. A medicine woman's source book. Boston: Beacon Press.

Hart, M. A. (1996). Sharing circles: Utilizing traditional practice methods for teaching, helping and supporting. In S. O'Meara \& D. West, A (Eds.), From our eyes: Learning from Indigenous peoples (pp. 59-72). Toronto: Garamond Press.

Hart, M. A. (2002). Seeking mino-pimatisiwin. Halifax: Fernwood Publishing.

Heilbron, C., L., \& Guttman, M. A. J. (2000). Traditional healing methods with First Nations women in Group Counselling. Canadian Journal of Counselling, 34(1), 3-13.

Henderson, J. Y. (2000a). Ayukpachi: Empowering Aboriginal thought. In M. Battiste (Ed.), Reclaiming Indigenous voice and vision (pp. 248-278). Vancouver, BC: UBC Press.

Henderson, J. Y. (2000b). Postcolonial ghost dancing: Diagnosing European colonialism. In M. Battiste (Ed.), Reclaiming Indigenous voice and vision (pp. 57-76). Vancouver, BC: UBC Press.

Holmes, L. (2000). Heart knowledge, blood memory, and the voice of the land: Implications of research among Hawaiian elders. In G. Dei, J.S. \& B. L. Hall (Eds.), Indigenous knowledges in global contexts (pp. 37-53). Toronto: University of Toronto Press.

Kenny, C. (2000). A sense of place: Aboriginal research as ritual practice. In R. Neil (Ed.), Voices of the drum: Indigenous education and culture (pp. 139150). Brandon, Manitoba: Kingfisher Publications.

Kovach, M. (2005). Emerging from the margins: Indigenous methodologies. In L. Brown \& S. Strega (Eds.), Research as resistance: critical, indigenous, \& anti-oppressive approaches (pp. 19-36). Toronto: Canadian Scholars Press.

LaRocque, E. (1991). Racism runs through Canadian society. In O. McKague (Ed.), Racism in Canada (pp. 73-76). Saskatoon: Fifth Street Publishers. 


\section{First Peoples Child \& Family Review, Volume 5, Number 2, 2010}

Little Bear, L. (2000). Jagged worldviews colliding. In M. Battiste (Ed.), Reclaiming Indigenous Voice and Vision (pp. 77-85). Vancouver: UBC Press.

Marsden, D. (2005). Indigenous wholistic theory for health: Enhancing traditionalbased Indigenous health services in Vancouver. Unpublished Doctor of Philosophy, University of British Columbia, Vancouver.

Marsden, D. (2006). Creating and sustaining positive paths to health by restoring traditional-based Indigenous health-education practices. Canadian Journal of Native Education, 29(1).

Martin, K. (2002). Ways of knowing, ways of being and ways of doing: Developing a theoretical framework and methods for Indigenous re-search and Indigenist research. Unpublished manuscript.

Monture-Angus, P. (1995). Thunder in my soul. A Mohawk woman speaks. Halifax: Fernwood Publishing.

McCormick, R. (2005). The healing path: What can counselors learn from Aboriginal people about how to heal? In R. Moodley \& W. West (Eds.), Integrating traditional healing practices into counselling and psychotherapy (pp. 293-304). Thousand Oaks: Sage Publications, Inc.

McPherson, D. H., \& Rabb, J. D. (2001). Indigeneity in Canada: Spirituality, the sacred and survival. International Journal of Canadian Studies, 23(Spring), 57-79.

Nabigon, H. (2006). The hollow tree. Fighting addiction with traditional native healing. Montreal \& Kingston: McGill-Queen's University Press.

Poonwassie, A., \& Charter, A. (2001). An Aboriginal worldview of helping: Empowering approaches. Canadian Journal of Counselling, 35(1), 63-73.

Poonwassie, A., \& Charter, A. (2005). Aboriginal worldview of healing: Inclusion, blending, and bridging. In R. Moodley \& W. West (Eds.), Integrating traditional healing practices into counselling and psychotherapy (pp. 15-25). Thousand Oaks: Sage Publications, Inc.

Rigney, L. (1999). Internalization of an Indigenous anticolonial cultural critique of research methodologies. A guide to Indigenist research methodology and its principles. Wicaso SA Review: Journal of Native American Studies Review, 14(2), 109-121.

Ross, L. (2005). Personalizing methodology: Narratives of imprisonment. In I. Hernandez-Avila (Ed.), Reading Native American women: Critical / creative representations (pp. 39-63). New York: Altamira Press.

Simpson, L. (2001). Aboriginal peoples and knowledge: Decolonizing our processes. The Canadian Journal of Native Studies, XXI(1), 137-148.

Sinclair, R. (2003). Indigenous research in social work: The challenge of operationalizing worldview. Native Social Work Journal, 5, 117-139.

Sinclair, R., Hart, M., \& Bruyere, G. (Eds.). (2009). Wicihitowin Aboriginal Social Work in Canada. Winnipeg: Fernwood Publishing.

Smith, L. T. (2000). Kaupapa Maori research. In M. Battiste (Ed.), Reclaiming indigenous voice and vision (pp. 225-247). Vancouver: UBC Press.

Solomon, A., \& Wane, N. N. (2005). Indigenous healers and healing in a modern world. In R. Moodley \& W. West (Eds.), Integrating traditional healing practices in counselling and psychotherapy (pp. 52-60). Thousand Oaks: Sage Publications, Inc.

Steinhauser, P. (2001). Situating myself in research. Canadian Journal of Native Education, 25(2), 183-187.

Talbot, S. (2002). Academic Indianismo: Social scientific research in American Indian studies. American Indian Culture and Research Journal, 26(4), 67-96.
TeHennepe, S. (1997). Respectful research: This is what my people say, you learn it from the story. In S. De Castell \& M. Bryson (Eds.), Radical In<ter>ventions: Identity, politics, and difference/s in educational praxis (pp. 153-182). New York: State University of New York Press.

Thomas, R. A. (2005). Honouring the oral traditions of my ancestors through storytelling. In L. Brown \& S. Strega (Eds.), Research as resistance: critical, indigenous, \& anti-oppressive approaches (pp. 237-254). Toronto: Canadian Scholars' Press.

Wa Thiong'o, N. (1986). Decolonising the mind: The politics of language in African literature. Oxford, U.K.: James Currey / Heinemann.

Weenie, A. (1998). Aboriginal pedagogy: The sacred circle concept. In L. Stiffarm, A. (Ed.), As we see ... Aboriginal pedagogy (pp. 59-66). Saskatoon: University Extension Press.

Wesley-Esquimaux, C. \& Smolewski, M. (2004). Historic Tauma and Aboriginal Healing. Ottawa: The Aboriginal Healing Foundation.

Wilson, S. (2001). What is an Indigenous research methodology? Canadian Journal of Native Education, 25(2), 175-179.

Wilson, S. (2003). Progressing toward an Indigenous research paradigm in Canada and Australia. Canadian Journal of Native Education, 27(2), 161-178. 